\title{
PENGGUNAAN REGRESI STEPWISE UNTUK MENENTUKAN FAKTOR YANG MEMPENGARUHI MOTIVASI SANTRI MELANJUTKAN STUDI KE PERGURUAN TINGGI (STUDI KASUS SMK IBNU CHOLIL BANGKALAN)
}

\author{
Ria Faulina \\ Program Studi Pendidikan Matematika STKIP PGRI Bangkalan \\ e-mail: riafaulina@stkippgri-bkl.ac.id
}

\begin{abstract}
People of Bangkalan in Madura Island, as the area closest to the Metropolitan Municipality of Surabaya, have low level of awareness of education, Evidence showed that many students were reluctant to continue their education to a higher level. It is because social culture and economic factors of the student. This research reviewed the motivation of santri boarding (Islamic Student) to continue their study into college from economic aspects so we can know the factors affecting the motivation of students to continue their studies into college. The study was conducted in SMK Ibn Cholil Bangkalan by collecting data through questionnaires. The data collected were analysed stepwise regression method, the result stated that only the father's occupation variable has significant influence. The higher the father's occupation, the greater the need for students to continue their studies to university.
\end{abstract}

Keywords: islamic boarding, stepwise regression, university

\begin{abstract}
ABSTRAK
Masyarakat Kabupaten Bangkalan, sebagai wilayah terdekat Pulau Madura dengan Kota Metropolitan Surabaya, mempunyai tingkat kesadaran akan pendidikan yang masih sangat rendah yang dibuktikan dengan banyaknya siswa yang enggan melanjutkan pendidikan ke jenjang yang lebih tinggi. Hal ini dikarenakan kondisi sosial budaya dan faktor ekonomi dari siswa yang bersangkutan. Dalam penelitian ini dikaji motivasi santri untuk melanjutkan studi ke perguruan tinggi dari segi ekonomi sehingga diketahui faktor yang mempengaruhi motivasi santri untuk melanjutkan studi ke perguruan tinggi. Penelitian dilakukan di SMK Ibnu Cholil Kabupaten Bangkalan dengan pengambilan data melalui kuesioner. Analisa dilakukan dengan menggunakan regresi Stepwise menghasilkan bahwa hanya variabel pekerjaan ayah yang mempunyai pengaruh signifikan. Semakin tinggi pekerjaan ayah, semakin besar pula keinginan siswa untuk melanjutkan studi ke perguruan tinggi.

Kata kunci: perguruan tinggi, pesantren, regresi stepwise
\end{abstract}

Pendidikan merupakan tonggak kemajuan suatu bangsa. Kualitas sumber daya manusia Indonesia menentukan nasib bangsa Indonesia ke depannya. Semakin tinggi kualitas sumber daya manusia, semakin besar peluang bangsa Indonesia untuk menjadi negara yang makmur dan maju. Berbagai upaya pemerintah untuk meningkatkan kualitas sumber daya manusia telah dilakukan. Salah satu upaya pemerintah dalam peningkatan kualitas sumber daya manusia Indonesia adalah 
melalui bidang pendidikan, misalnya dengan adanya program wajib belajar 12 tahun dimana program ini dimaksudkan untuk menekan angka buta huruf dan meningkatkan kualitas sumber daya manusia.

Kabupaten Bangkalan terletak di bagian barat Pulau Madura dengan luas wilayah 1.260,14 km2. Kabupaten ini merupakan wilayah terdekat Pulau Madura dengan Kota Metropolitan Surabaya. Walaupun dari segi letaknya yang strategis, angka partisipasi pendidikan di Bangkalan masih sangat rendah yang dibuktikan dengan banyaknya siswa yang enggan melanjutkan pendidikan ke jenjang yang lebih tinggi (Ahmad, 2016). Penyebabnya antara lain faktor ekonomi, budaya-agama, politik, sosial, ketenagakerjaan, sarana-prasarana, guru sampai ke faktor psiko-sosial(Sukarno, 2015). Budaya masyarakat umumnya cenderung mengikuti pandangan kyai/tokoh agama bahwa pesantren lebih menyangkut kebutuhan primer dan mendasar dibanding sistem persekolahan/formal. Disamping itu, faktor ekonomi juga menjadi pertimbangan para santri untuk melanjutkan studi ke perguruan tinggi. Permasalahan dalam penelitian ini meliputi hubungan antara motivasi para santri untuk melanjutkan studi ke perguruan tinggi dengan faktor ekonomi orang tua danfaktor yang paling berpengaruh terhadap motivasi para santri untuk melanjutkan studi ke perguruan tinggi.

Penelitian mengenai motivasi untuk melajutkan studi ke perguruan tinggi telah banyak dilakukan, baik terhadap siswa maupun santri. Kharisma dan Latifah (2015) meneliti tentang pengaruh motivasi, prestasi belajar, status sosial ekonomi orang tua dan lingkungan teman sebaya terhadap minat melanjutkan pendidikan ke perguruan tinggi pada siswa kelas XII kompetensi keahlian akuntansi di SMK Negeri se-kota Semarang tahun ajaran 2014/2015. Hasil penelitian menunjukkan bahwa motivasi, prestasi belajar, status sosial ekonomi orang tua, dan lingkungan teman sebaya secara simultan berpengaruh sebesar $71,5 \%$ terhadap minat melanjutkan pendidikan ke perguruan tinggi. Sedangkan motivasi berpengaruh sebesar $17,47 \%$ terhadap minat melanjutkan pendidikan ke perguruan tinggi secara parsial, prestasi belajar berpengaruh sebesar $23,91 \%$ terhadap minat melanjutkan pendidikan ke perguruan tinggi secara parsial, status sosial ekonomi orang tua berpengaruh sebesar $16,81 \%$ terhadap minat melanjutkan pendidikan ke perguruan tinggi secara parsial, dan lingkungan teman sebaya berpengaruh sebesar 10,50\% terhadap minat melanjutkan pendidikan ke perguruan tinggi secara parsial. Penelitian lain yang menjadi pendukung penelitian ini adalah penelitian oleh Sugiarti (2010) mengenai motivasi wali santri menyekolahkan anaknya di Pondok Pesantren Al Mukmin Ngruki Sukoharjo.

Kedua penelitian di atas menjadi dasar penulis melakukan penelitian motivasi melanjutkan studi ke perguruan tinggi bagi santri SMK Ibnu Cholil Bangkalan. Penelitian ini diharapkan dapat membantu pihak/instansi terkait seperti Departemen Agama Kabupaten Bangkalan serta Dinas Pendidikan dan Kebudayaan Kabupaten Bangkalan dalam menentukan kebijakan terkait peningkatan mutu pendidikan di Kabupaten Bangkalan.

Berdasarkan Kamus Besar Bahasa Indonesia (2015), definisi motivasi adalah dorongan yang timbul pada diri seseorang untuk melakukan sesuatu secara sadar maupun tidak sadar dengan tujuan tertentu. Motivasi menentukan seseorang untuk mau bekerja giat melakukan sesuatu hal sehingga mendapatkan hasil yang optimal.

Kata santri menurut Kamus Besar Bahasa Indonesia (2015) berarti orang yang mendalami agama Islam di suatu tempat. Sedangkan pesantren adalah lembaga pendidikan Islam dimana para santri biasa tinggal di pondok (asrama). Materi pengajaran kitab-kitab klasik dan kitab-kitab umum bertujuan agar para santri menguasai ilmu agama Islam secara detail serta mengamalkannya sebagai pedoman hidup keseharian dengan menekankan pentingnya moral dalam kehidupan bermasyarakat. 


\section{Analisis Regresi Linier Berganda}

Regresi linear ganda adalah persamaan regresi yang menggambarkan hubungan antara lebih dari satu variabel bebas $\left(X_{1}, X_{2}, \ldots X_{k}\right)$ dan satu variabel tak bebas $(Y)$. Secara matematis hubungan variabel-variabel tersebut dapat dituliskan sebagai berikut (Walpole, Myers, Myers, \& Ye, 2012).

$$
Y=\beta_{0}+\beta_{1} X_{1}+\cdots+\beta_{k} X_{k}+\varepsilon_{i}
$$

$Y=$ Variabel tak bebas, $X=$ Variabel bebas, $\beta_{0}=$ intersep/perpotongan dengan sumbu tegak, $\beta_{1}, \beta_{2}$, $\ldots ., \beta_{\mathrm{k}}=$ parameter model regresi, $\varepsilon_{\mathrm{i}}$ saling bebas dan berdistribusi normal $N\left(0, \sigma^{2}\right), i=1,2, \ldots, n$

Estimasi model regresi linier berganda adalah :

$$
\widehat{Y}=b_{0}+b_{1} X_{1}+\cdots+b_{k} X_{k}
$$

Proses selanjutnya setelah melakukan pendugaan parameter model regresi berganda adalah pengujian terhadap model regresi apakah signifikan atau tidak. Pengujian dilakukan dengan ANAVA (Analisis Variansi).

$$
\begin{aligned}
& J K T=\sum_{i=1}^{n}\left(y_{i}-\bar{y}\right)^{2} \\
& J K R=\sum_{i=1}^{n}\left(\hat{y}_{i}-\bar{y}\right)^{2} \\
& J K G=\sum_{i=1}^{n}\left(y_{i}-\hat{y}_{i}\right)^{2}
\end{aligned}
$$

Hipotesis yang harus diuji dalam analisis regresi ganda adalah:

$H_{0}: \beta_{1}=\beta_{2}=\ldots=\beta_{k}=0$

$H_{1}$ : Tidak semua $\beta_{k}(k=1,2, \ldots, p-1)$ yang tidak sama dengan nol

$H_{0}$ ditolak jika $F_{\text {hit }}>F_{\text {tabel, }}$ yang berarti model regresi signifikan atau ada hubungan liner antara $X$ dan Y.

Tabel 1. Anava untuk Pengujian pada Model Regresi Linier Berganda.

\begin{tabular}{cccccc}
\hline $\begin{array}{c}\text { Sumber } \\
\text { Keragaman }\end{array}$ & $\mathrm{db}$ & $\begin{array}{c}\text { Jumlah } \\
\text { Kuadrat }\end{array}$ & $\mathrm{KT}$ & Fhit & Ftabel \\
\hline Regresi & $\mathrm{k}$ & $\mathrm{JKR}$ & $\mathrm{KTR}=\mathrm{JKR} / \mathrm{k}$ & $\mathrm{F}_{\text {hit }}=\mathrm{KTR} / \mathrm{KTG}$ & $\mathrm{F}_{\mathrm{a}(\mathrm{k}, \mathrm{n}-\mathrm{k}-\mathrm{l})}$ \\
Galat & $\mathrm{n}-\mathrm{k}-1$ & $\mathrm{JKG}$ & $\mathrm{KTG}=\mathrm{JKG} /(\mathrm{n}-\mathrm{k}-1)$ & & \\
\hline Total & $\mathrm{n}-1$ & $\mathrm{JKT}$ & & & \\
\hline
\end{tabular}

Asumsi yang harus dipenuhi dalam analisis regresi ganda adalah: Tidak ada multikolinearitas (tidak ada korelasi antara variabel independen); Homo roskedastisitas (variansi error konstan); Normalitas (error mempunyai sebaran normal); Tidak ada autokorelasi (error bersifat acak).

Regresi stepwise melibatkan dua jenis proses yaitu: forward selection dan backward elimination. Pada masing-masing tahapan, terjadi proses memutuskan variabel mana yang merupakan prediktor terbaik untuk dimasukkan ke dalam model. Hal ini ditentukan berdasarkan uji F parsial. Jika nilai F-parsial variabel yang dimasukkan lebih kecil dibandingkan nilai $F$ tabel yang 
ditetapkan maka variabel dihilangkan. Proses ini dilakukan terus menerus hingga tidak ada lagi variabel yang memenuhi kriteria untuk ditambahkan atau dihilangkan (Draper \& Smith, 1998).

\section{METODE}

Penelitian ini menggunakan pendekatan kuantitatif dengan metode survei melalui pemberian angket kuesioner. Penelitian dilakukan di SMK Ibnu Cholil Bangkalan dan subjek yang digunakan adalah santri yang telah memasuki tahun terakhir pendidikan. Teknik pengambilan sampel dalam penelitian ini adalah total sampling dimana sampling diambil dari seluruh populasi. Hal ini dikarenakan populasi santri yang memasuki tahun terakhir pendidikan SMK Ibnu Cholil sebanyak 30 orang.

Faktor yang digunakan sebagai variabeldalam penelitian ini mengacu pada penelitian yang dilakukan oleh Sari (2013). Variabel dibedakan menjadi dua, yaitu variabel bebas dan variabel tak bebas. Variabel bebas meliputi pekerjaan ayah (X1), pekerjaan ibu (X2), pendidikan terakhir ayah (X3), pendidikan terakhir ibu (X4), pendapatan orang tua perbulan (X5), dan pengeluaran orang tua perbulan (X6). Sedangkan variabel tak bebas adalah keinginan melanjutkan ke perguruan tinggi (Y). Metode yang digunakan dalam penelitian ini mengacu pada penelitian yang dilakukan oleh Kharisma dan Latifah (2015) yaitu analisis deskriptif statistik dan statistik inferensial analisis regresi bergandadengan regresi stepwise. Analisis data inferensial diolah dengan menggunakan program SPSS dengan tingkat kepercayaan $95 \%$ atau alpha 0,05 .

\section{Hasil dan Pembahasan}

Pada bagian ini, akan diuraikan hasil penelitian yang dibedakan menjadi dua bagian, yaitu analisis deskriptif dan analisis statistika inferensial. Pada analisis statistika inferensial, akan diuraikan penggunaan regresi linier berganda dan regresi stepwise serta uji-uji yang harus dipenuhi dalam pemodelan dengan regresi.

Sebelum dilakukan analisis variabel/faktor yang berpengaruh terhadap motivasi para santri untuk melanjutkan studi ke perguruan tinggi, perlu dilakukan telaah penilaian santri terhadap keinginan melanjutkan studi. Penilaian tersebut meliputi deskripsi santri yang tertarik melanjutkan studi ke perguruan tinggi, perguruan tinggi yang diinginkan, bidang ilmu perguruan tinggi, dan alasan tidak melanjutkan studi.

Gambar 1 menunjukkan penilaian santri terhadap keinginan melanjutkan studi yang meliputi deskripsi santri yang tertarik melanjutkan studi ke perguruan tinggi, perguruan tinggi yang diinginkan, bidang ilmu perguruan tinggi, dan alasan tidak melanjutkan studi. Dari 30 siswa Kelas XII SMK Ibnu Cholil Kabupaten Bangkalan terdapat 22 siswa tertarik melanjutkan studi ke perguruan tinggi sedangkan 8 siswa lainnya tidak tertarik melanjutkan studi ke perguruan tinggi. Dari 22 siswa yang tertarik melanjutkan studi ke perguruan tinggi, sebagian besar tertarik melanjutkan ke PTN (15 siswa) dan 7 siswa lainnya memilih melanjutkan studi ke PTS. Terkait bidang ilmu peminatan, bidang teknologi (8 siswa) dan sosial (7 siswa) lebih banyak diminati dibandingkan bidang lain yaitu MIPA ( 3 siswa) dan bidang ilmu lainnya (4 siswa, dimana 2 siswa tertarik di bidang pendidikan dan 2 siswa lain di bidang kesehatan). Siswa yang tidak tertarik melanjutkan studi ke perguruan tinggi sebagian besar disebabkan oleh faktor ketidaktertarikan (4 siswa), masalah keuangan (2 orang), dan faktor lainnya (2 orang). 


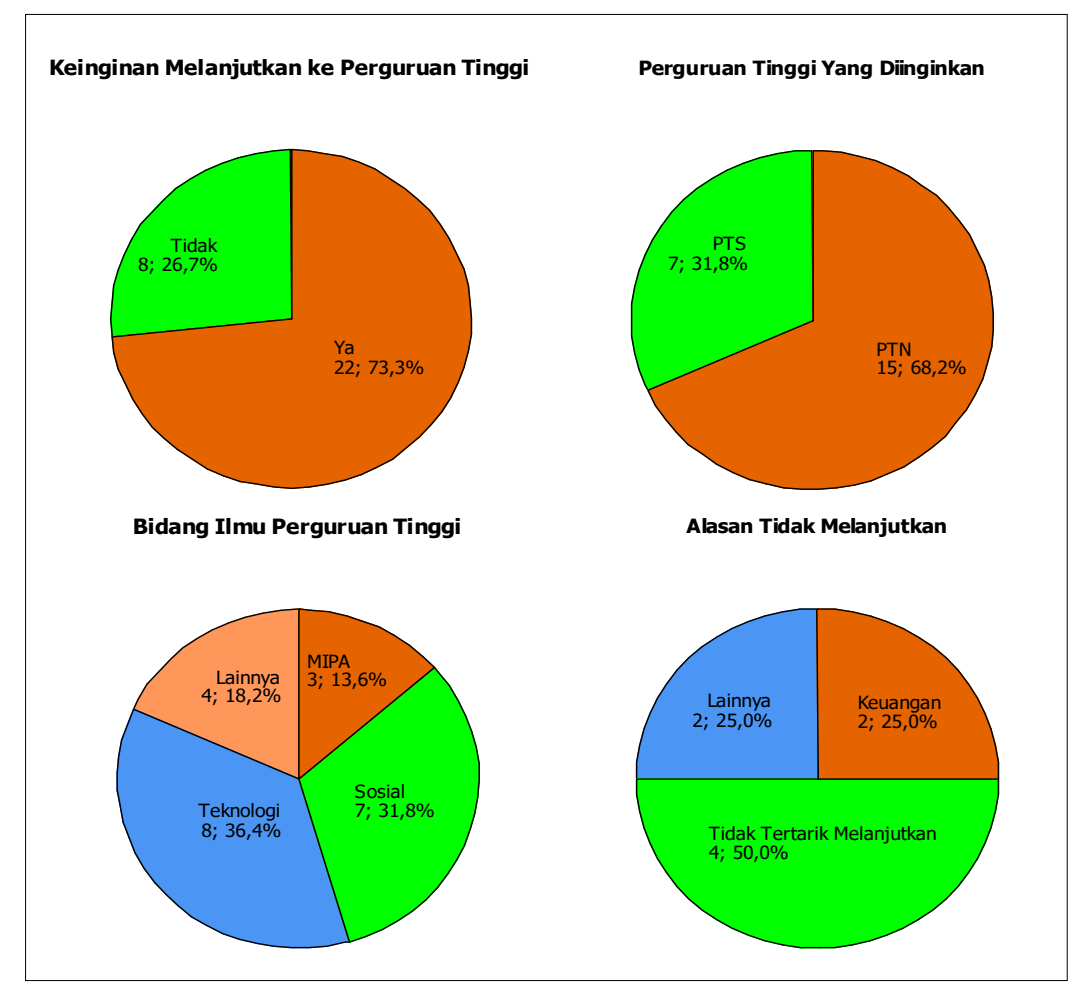

Gambar 1. Deskriptif penilaian santri terhadap keinginan melanjutkan studi ke perguruan tinggi

Persamaan regresi yang dihasilkan berdasarkan analisis regresi linier berganda adalah sebagai berikut.

$$
Y=0,113 X_{1}-0,29 X_{2}+0,191 X_{3}+0,211 X_{4}+0,316 X_{5}-0,267 X_{6}
$$

Persamaan regresi yang dihasilkan mempunyai $\mathrm{R}-\mathrm{Sq} 0,85$, artinya $85 \%$ keragaman data dapat dijelaskan oleh variabel dalam model regresi yaitu variabel pekerjaan ayah $\left(X_{1}\right)$, pekerjaan ibu $\left(X_{2}\right)$, pendidikan ayah $\left(X_{3}\right)$, pendidikan ibu $\left(X_{4}\right)$, pendapatan orangtua $\left(X_{5}\right)$, dan pengeluaran orang tua $\left(X_{6}\right)$. Sedangkan sisanya sebesar $15 \%$ dijelaskan oleh variabel lainnya. Nilai $F=22,752$ dengan P-value $=0,000$ menunjukkan bahwa variabel pekerjaan ayah, pekerjaan ibu, pendidikan ayah, pendidikan ibu, pendapatan orangtua, dan pengeluaran orang tua secara serentak mempengaruhi motivasi para santri untuk melanjutkan studi ke perguruan tinggi dengan tingkat kepercayaan 95\%. Pengujian signifikansi estimasi per variabel dapat dilihat pada Tabel 2. Variabel yang signifikan pada tingkat kepercayaan $95 \%$ hanya terdapat pada variabel pendapatan orang tua. Nilai P-value pada variabel pendapatan orang tua sebesar 0,034 lebih kecil dari $a=0,05$. Sedangkan untuk variabel lainnya yaitu pekerjaan ayah, pekerjaan ibu, pendidikan ayah, pendidikan ibu, dan pengeluaran orang tua perbulan tidak signifikan karena $P$-value mempunyai nilai lebih dari $a=0,05$. 

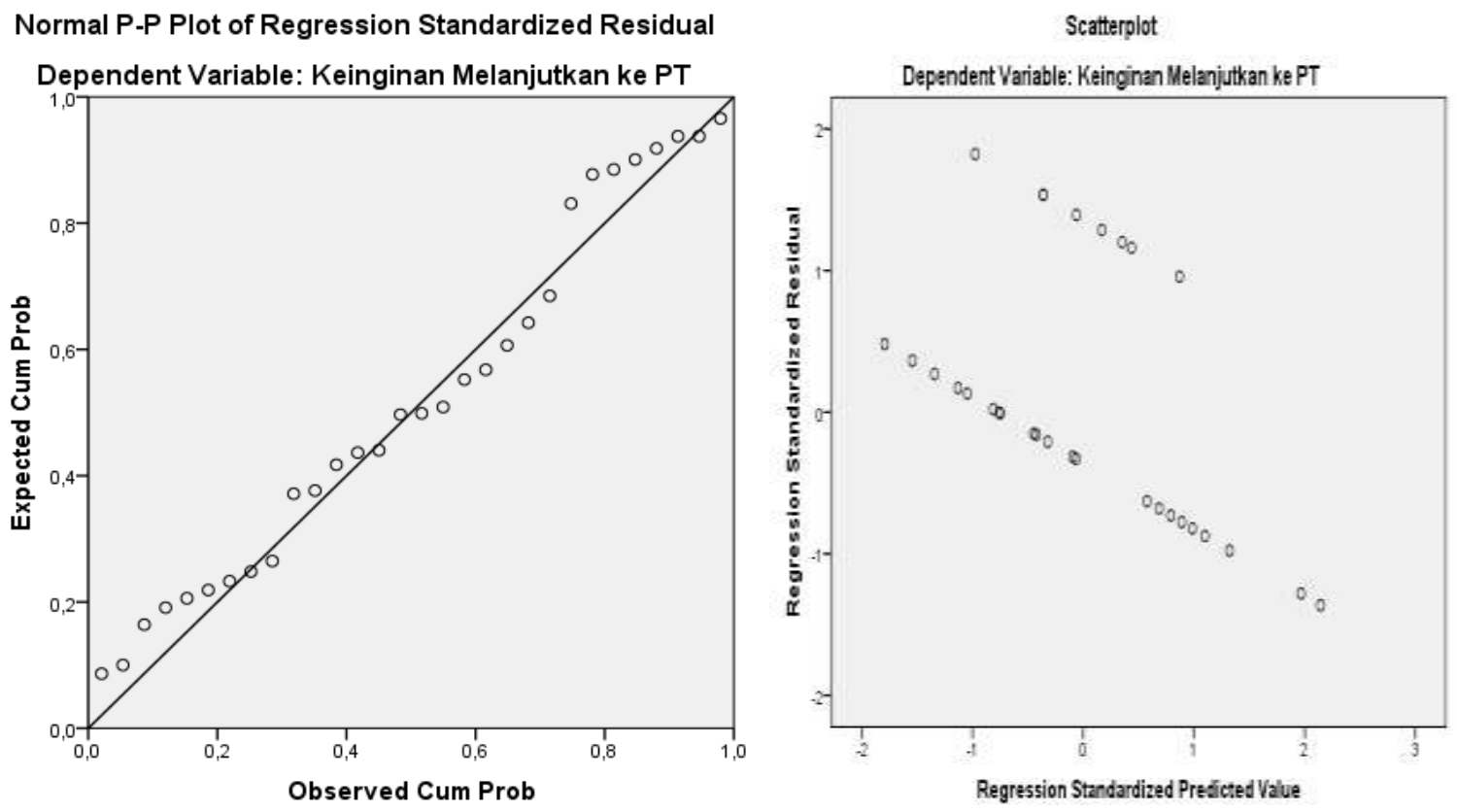

Gambar 2. Plot normalitas dan heteroskedastisitas residual analisis regresi linier

Tabel 2. Hasil Uji Regresi Linier Berganda untuk Semua Variabel.

\begin{tabular}{|c|c|c|c|c|c|}
\hline Variabel & $\begin{array}{c}\text { Signifikansi } \\
\text { estimasi } \\
\text { koefisien }\end{array}$ & VIF & Heteroskedastisitas & Autokorelasi & Normalitas \\
\hline Pekerjaan Ayah $\left(\mathrm{X}_{1}\right)$ & $0,108^{* *}$ & 2,667 & Tidak terpenuhi & Tidak Terpenuhi & Terpenuhi \\
\hline Pekerjaan Ibu $\left(\mathrm{X}_{2}\right)$ & $0,571^{* *}$ & 4,185 & & & \\
\hline Pendidikan Ayah $\left(X_{3}\right)$ & $0,323^{* *}$ & $15,372^{*}$ & & & \\
\hline Pendidikan Ibu $\left(\mathrm{X}_{4}\right)$ & $0,220^{* *}$ & $11,621^{*}$ & & & \\
\hline $\begin{array}{l}\text { Pendapatan Orang Tua Per } \\
\text { Bulan }\left(X_{5}\right)\end{array}$ & 0034 & $15064 *$ & & & \\
\hline $\begin{array}{l}\text { Bulan }\left(X_{5}\right) \\
\text { Pengeluaran Orang Tua Per }\end{array}$ & 0,004 & $75,064^{*}$ & & & \\
\hline Bulan $\left(X_{6}\right)$ & 0,080 & $12,148^{*}$ & & & \\
\hline
\end{tabular}

${ }^{*}$ nilai VIF $>10$; ${ }^{* *}$ variabel yang tidak signifikan pada $a=5 \%$

Berikut disajikan pengujian asumsi model regresi (Tabel 2). Pada variabel pendidikan ayah, pendidikan ibu, pendapatan orang tua perbulan, dan pengeluaran orang tua perbulan terjadi kasus multikolinieritas atau terjadi korelasi yang kuat antarvariabel tersebut. Nilai $d=2,455$ berada diantara (4-dU) dan (4-dL), atau antara 2,0687 sampai 3,0018. Hal ini menunjukkan bahwa setiap error antarpengamatan belum dapat dikatakan saling independen maupun berkorelasi. Pengujian asumsi heteroskedastisitas menggunakan metode plotting antara nilai prediksi terstandardisasi/dibakukan dengan nilai residual yang dibakukan. Pada pengujian ini, titik-titik pada plot menunjukkan pola. Adanya pola pada plot nilai prediksi terstandardisasi dengan nilai residual yang dibakukan menunjukkan adanya ketidaksamaan pada variansi error di setiap data yang diperoleh dari persamaan regresi. Dari pengujian asumsi model regresi, hanya satu asumsi yang terpenuhi, yaitu 
normalitas error persamaan regresi. Akibat adanya beberapa asumsi yang tidak terpenuhi mengakibatkan perolehan model regresi tidak sesuai untuk digunakan dalam kasus ini.

Adanya kasus multikolinieritas dapat disebabkan oleh adanya variabel tidak signifikan dalam model regresi. Variabel pekerjaan ayah, pekerjaan ibu, pendidikan ayah, dan pendidikan ibu merupakan variabel yang tidak signifikan pada tingkat kepercayaan 95\%. Untuk mengatasi permasalahan dalam regresi linier berganda dengan kasus multikolinieritas dapat digunakan regresi dengan metode Stepwise. Adapun persamaan regresi dengan metode Stepwise adalah sebagai berikut.

$$
Y=0,545 X_{1}
$$

Persamaan regresi dengan metode Stepwise mempunyai R-Sq sebesar 0,797 artinya 79,7\% keragaman data dapat dijelaskan oleh variabel dalam model regresi yaitu variabel pekerjaan ayah dan 20,3\% lainnya dijelaskan oleh variabel lain. Nilai $F=113,901$ dengan nilai $P$-value 0,000 lebih kecil dari $\alpha=0,05$ yang berarti variabel dalam model berpengaruh terhadap motivasi para santri untuk melanjutkan studi ke perguruan tinggi dengan tingkat kepercayaan $95 \%$. Untuk pengujian signifikansi estimasi variabel, variabel pekerjaan ayah signifikan terhadap model regresi dengan nilai koefisien 0,545, $\mathrm{t}=10,672$ dan P-value $=0,000$

Sama halnya dengan pemodelan regresi sebelumnya, model regresi dengan metode Stepwise juga harus memenuhi asumsi normalitas error regresi, homoskedastisitas variansi error, independensi antarvariabel (tidak terdapat multikolinieritas), dan independensi antarpengamatan (tidak terjadi autokorelasi).
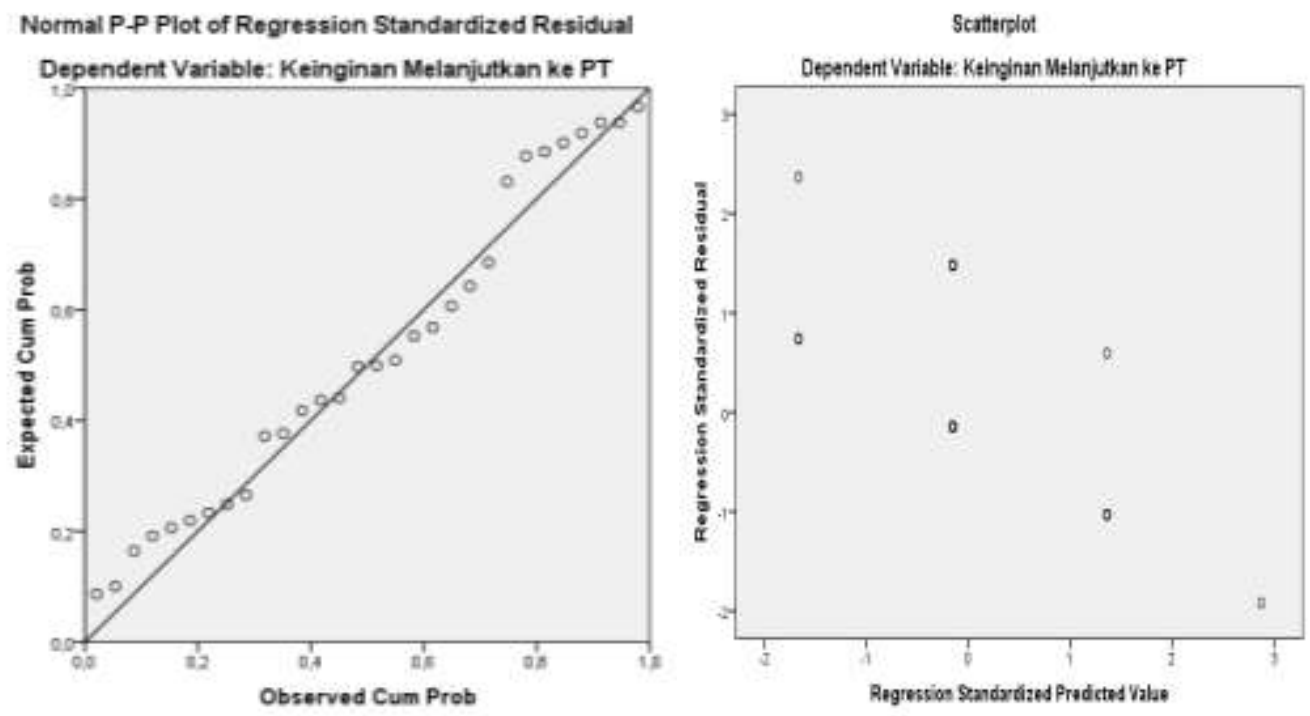

Gambar 3. Plot normalitas dan heteroskedastisitas residual analisis regresi Stepwise

Adapun hasil pengujian asumsi dalam model regresi Stepwise adalah sebagai berikut: Pertama, pengujian normalitas error regresi. Pada normal p-p plot, titik-titik menyebar di sekitar garis diagonal dan mengikuti arah garis diagonal sehingga model regresi memenuhi asumsi normalitas. Kedua, pengujian independensi antarvariabel. Tidak terjadi kasus multikolinieritas dikarenakan nilai $\mathrm{VIF}=1<10$. Ketiga, pengujian independensi antarpengamatan. Nilai $d=2,279, \mathrm{dL}=1,352$, dan $\mathrm{dU}=$ 
1,4894. Nilai d berada diantara du dan (4-dU), atau antara 1,4894 sampai 2,5106. Hal ini menunjukkan tidak ada autokorelasi pada data, artinya setiap error antarpengamatan saling independen. Keempat, pengujian asumsi heteroskedastisitas menggunakan metode plotting antara nilai prediksi terstandardisasi/dibakukan dengan nilai residual yang dibakukan. Pada pengujian ini, titik-titik pada plot menunjukkan tidak adanya pola.

Dari pengujian asumsi model regresi Stepwise, model regresi yang terbentuk telah memenuhi semua asumsi, yaitu asumsi normalitas error regresi, homoskedastisitas variansi error, independensi antarvariabel (tidak terdapat multikolinieritas), dan independensi antarpengamatan (tidak terjadi autokorelasi). Estimasi koefisien persamaan regresi dan pengujian serentak (F) juga telah terpenuhi yang menunjukkan model regresi Stepwise sesuai untuk digunakan dalam kasus analisis motivasi para santri untuk melanjutkan studi ke perguruan tinggi. Dari persamaan yang terbentuk, peningkatan pekerjaan ayah berpengaruh positif terhadap peningkatan keinginan melanjutkan studi ke perguruan tinggi. Jika variabel pekerjaan ayah (X1) mengalami peningkatan satu satuan, maka variabel $Y$ (keinginan melanjutkan studi ke perguruan tinggi) akan mengalami peningkatan sebesar 0,545 . Semakin tinggi pekerjaan ayah, semakin besar pula keinginan siswa untuk melanjutkan studi ke perguruan tinggi, dengan perumusan. Keinginan Melanjutkan Studi Ke Perguruan Tinggi $=0,545$ Pekerjaan Ayah.

\section{SIMPULAN}

Dari hasil analisis, dapat disimpulkan bahwa berdasarkan regresi stepwise, keinginan melanjutkan studi ke perguruan tinggi dipengaruhi oleh pekerjaan ayah. Semakin tinggi status pekerjaan ayah, semakin besar pula keinginan siswa untuk melanjutkan studi ke perguruan tinggi. Dengan kata lain, untuk meningkatkan kualitas SDM generasi muda khususnya di lingkungan SMK Ibnu Cholil Bangkalan, perlu adanya upaya peningkatan taraf hidup keluarga, khususnya melalui peningkatan level pekerjaan ayah.

\section{REFERENSI}

Ahmad, H. (2016). Tingkat pendidikan warga bangkalan dinilai masih rendah. Dipetik September 11, 2016, dari http://www.maduracorner.com/bangkalan/\%E2\%80\%8Btingkat-pendidikan-wargabangkalan-dinilai-masih-rendah/.

Draper, N. R., \& Smith, H. (1998). Applied regression analysis (Third ed.). New York: Wiley.

Kharisma, N., \& Latifah, L. (2015). Pengaruh Motivasi, Prestasi Belajar, Status Sosial Ekonomi Orang Tua dan Lingkungan Teman Sebaya Terhadap Minat Melanjutkan Pendidikan Ke Perguruan Tinggi Pada Siswa Kelas XII Kompetensi Keahlian Akuntansi Di SMK Negeri Se-Kota Semarang Tahun Ajaran 2014/2015. Economic Education Analysis Journal, 4(3), 833-846.

Sari, I. P. (2013). Analisis minat siswa sma ibrahimy sukorejo melanjutkan ke iaii sukorejo menggunakan regresi logistik biner dan multi korespondensi. Skripsi, Institut Pertanian Bogor, Departemen Statistika, Bogor.

Sugiarti, S. (2010). Motivasi wali santri menyekolahkan anaknya di pondok pesantren Al Mukmin Ngruki Sukoharjo. Skripsi, Universitas Muhammadiyah Surakarta, Program Studi Pendidikan Islam, Surakarta. 
Jurnal Matematika, Saint, dan Teknologi, Volume 18, Nomor 2, September 2017, 68-76

Sukarno, M. (2015). Dikhotomi pendidikan umum versus agama dan reproduksi masyarakat santri. Dipetik Desember 12, 2016, dari http://kependudukan.lipi.go.id/id/kajiankependudukan/pendidikan/241-dikhotomi-pendidikan-umum-versus-agama-dan-reproduksimasyarakat-santri.

Walpole, R. E., Myers, R. H., Myers, S. L., \& Ye, K. (2012). Probability \& statistics for engineers \& scientists (9 ed.). USA: Pearson Eduaction, Inc. 